\title{
EDUCAÇÃO POPULAR EM SAÚDE A PARTIR DE UM JOGO: GESTÃO E CUIDADO EM UMA UNIDADE DE SAÚDE DA FAMÍLIA
}

\author{
POPULAR HEALTH EDUCATION FROM A GAME: MANAGEMENT AND CARE IN A FAMILY \\ HEALTH UNIT
}

Bruno Souza Bechara Maxta ${ }^{1}$

Aline Barreto de Almeida ${ }^{2}$

Lucas Bronzatto Silveira ${ }^{3}$

Carla Soleman ${ }^{4}$

Márcia Niituma Ogata ${ }^{5}$

Resumo $\mathrm{O}$ presente relato apresenta a atividade 'bingão da saúde' como proposta diferenciada de gestão participativa e cuidado, em uma unidade de saúde, no contexto da Estratégia de Saúde da Família. A experiência é articulada com os pressupostos da política de humanização e da educação popular em saúde, com foco na democratização e na descentralização da gestão e cuidado, reconhecendo os usuários-cidadãos e os sujeitos-trabalhadores como atores de práticas coletivas no âmbito comunitário. É valorizada a cooperação e a disposição coletiva que permitem partilhar saberes e práticas de saúde. Através do jogo denominado 'bingo', são destacados temas, fala, pensamentos e interações como meio comum de expressões e significações comunitárias para os momentos da unidade de saúde. Esse processo vem permitindo o fortalecimento do vínculo profissional-usuário e a troca de saberes para a gestão em saúde em seus conselhos locais. Palavras-chave saúde da família; educação em saúde; participação comunitária.
Abstract This report presents the 'big health bingo' activity as a differentiated proposal for participatory management and care, at a health care unit, in the context of the Family Health Strategy. The experience is combined with the assumptions of the humanization and popular health education policy, focusing on the democratization and decentralization of management and care, recognizing the citizen-users and subjectemployees as agents of collective practices within the Community. Value is given to cooperation and collective willingness, which allow the sharing of knowledge and health practices. By means of the game called 'bingo,' themes, speeches, thoughts, and interactions are highlighted as a common means of community expression and meanings about the moments of health unit. This process has allowed the strengthening of the professional-user bond and the exchange of knowledge on health management in their local councils.

Keywords family health; health education; community participation. 


\section{Introdução}

A participação popular é um dos pilares da consolidação do Sistema Único de Saúde (SUS) no Brasil (Brasil, 1990; Valla, 1998). Historicamente, vem sendo posta em prática pelas mobilizações comunitárias e atuações de movimentos sociais que defendem a participação da população na organização, gestão e controle dos serviços e ações de saúde em órgãos colegiados, atualmente representados pelos conselhos e conferências de saúde (Acioli, 2005). Com este movimento, preconiza-se a concentração de esforços para garantir um real controle social (Paim, 1999) do setor. Para que isto aconteça, é apontada como necessária a transformação cultural da atenção aos usuários e da gestão dos processos de trabalho, pela aproximação e fortalecimento da relação entre profissionais e população, a partir de propostas de inovação das estruturas do serviço que visem a qualidade, eficiência e resolutividade (Brasil, 2006a).

As atuais propostas que norteiam a Estratégia de Saúde da Família (ESF) apontam para um processo de democratização das instituições (Crevelim; Peduzzi, 2005) que considera a comunidade, com suas vivências e saberes, como protagonista dos novos olhares sobre o território de abrangência do serviço, bem como sobre as reais necessidades de saúde locais, influenciando e readequando as práticas dos trabalhadores em saúde. Partindo deste conceito, os modelos de atenção e gestão passam necessariamente por colocar a comunidade e o usuário no centro do processo de formulação e operacionalização das políticas e ações de saúde locais. Busca-se ampliar a participação do usuário e consolidar a dialética da gestão como uma prerrogativa do trabalho em saúde.

No município de São Carlos, São Paulo, tal proposição vem orientando diversos dispositivos legais e governamentais que permitem o fortalecimento da participação popular e do controle social na ESF. Ainda que a institucionalização dos Conselhos Gestores Locais de Saúde (São Carlos, 2001) seja valorizada, são muitos os problemas de planejamento enfrentados pelas unidades de saúde para sua efetivação, os quais orientam desafios das mais diversas ordens comunitárias e institucionais.

A partir de 2007, residentes do Programa de Residência Multiprofissional em Saúde da Família e Comunidade da Universidade Federal de São Carlos (São Carlos, 2007) iniciam atividades de gestão e cuidado nas Unidades de Saúde da Família (USF) desse município, amparados pelas bases do Apoio Matricial em saúde, que vem sendo reconhecido como uma metodologia para a gestão do trabalho em saúde na perspectiva da clínica ampliada e da integração dialógica entre distintas especialidades e profissões em torno de objetivos comuns. Neste arranjo organizacional, são constituídas equipes interdisciplinares em saúde que objetivam assegurar 
retaguarda assistencial e suporte técnico-pedagógico às equipes que apoiam (Campos e Domitti, 2007).

Com atuação nessa perspectiva, a equipe de residentes da USF Romeu Tortorelli elencou a participação popular e o controle social como temas fundamentais a serem discutidos com a equipe local, já que o Conselho Gestor Local (CGL) desta USF é um espaço aceito e de importância reconhecida para a construção de idéias e tomadas de decisão com a comunidade. Sua proposta integra a comunidade, os seus conselheiros e a equipe da USF (Brasil, 2004) como corresponsáveis na governabilidade para a resolução de problemas institucionais e comunitários de saúde.

No entanto, mesmo valorizado pela comunidade e equipe como espaço de gestão participativa, o CGL apresentava algumas dificuldades, que foram levantadas com seus membros. Assim, na perspectiva de fortalecimento deste espaço, foram reconhecidos como desafios: o esvaziamento da participação da população nas reuniões do CGL; o pequeno número de representantes usuários do serviço nestes espaços; e a frágil relação estabelecida entre o trabalho realizado na USF e as ações do CGL.

Neste preocupante cenário, indagações surgiram, em reuniões de equipe, sobre como compreender interesses e mobilizar a comunidade da USF Romeu Tortorelli para participar nos espaços do CGL, ou mesmo em novos possíveis espaços de envolvimento com o sistema de saúde municipal. Seria realmente uma prioridade discutir assuntos comunitários? O que os usuários entendem e pensam sobre as reuniões do conselho gestor da USF? Como fazer com que a população se sensibilize e esteja presente na USF disposta a trabalhar assuntos coletivos e locais de saúde? Que ferramentas seriam utilizadas? Como seria essa mobilização? Como 'ganhar' dos programas televisivos e do conformismo assumido por parte dos profissionais do serviço e da comunidade quanto às ações em saúde realizadas? Várias idéias foram pensadas. Em uma das reuniões, ao se perguntar para os conselheiros o que as pessoas gostam de fazer no bairro quando não estão em casa, a resposta foi unânime: jogar bingo. Bingo! Estava aí a resposta e a ideia de se criar o 'bingão da saúde'.

As reuniões posteriores do CGL foram direcionadas para se pensar o 'bingão da saúde' como estratégia de participação popular integrada ao espaço de controle social instituído na USF. Nessa perspectiva, é aposta da USF a organização de momentos de convivência mais próximos com a comunidade, no sentido de aproximar os usuários da realidade da unidade, como também aproximar os profissionais da comunidade, de forma a constituir parcerias e discussões permanentes sobre temas variados em saúde, em particular para reorganizar o CGL, atualmente inativo.

Este artigo apresenta a atividade 'bingão da saúde' como espaço de gestão participativa e de reorganização do trabalho da USF Romeu Tortorelli, 
buscando evidenciar a sua contribuição para: a apropriação das necessidades dos conceitos e saberes populares em saúde; os momentos de formação e mobilização comunitária em saúde; a consolidação da participação em espaços de controle social; e o fortalecimento do vínculo entre a equipe de saúde da família e os usuários. Os aportes empíricos desta experiência são articulados com os pressupostos da política de humanização em saúde (Brasil, 2006a) e da educação popular em saúde (Vasconcelos, 2004), tendo como foco a democratização e a descentralização da gestão, bem como a importância dos usuários e dos trabalhadores da saúde como atores na implementação de práticas centradas na construção coletiva no âmbito comunitário (Campos, 2003).

\section{Apresentação da experiência}

O 'bingão da saúde' é uma atividade de interação comunitária que reúne mensalmente residentes multiprofissionais, profissionais da equipe mínima de referência e usuários da USF do bairro Romeu Tortorelli, município de São Carlos, São Paulo. Destacam-se a ação e a 'corresponsabilização' coletivas (Brasil, 2004) no processo de reorganização da ESF local pela reestruturação, ou mesmo, proposição de novas atividades para a USF e para o controle social. Para tanto, utiliza-se de proposta metodológica envolvendo a comunicação e a participação pela abordagem interativa e significativa em contextos populares (Freire, 1996; 1979). Sobre esta perspectiva, a comunicação é compreendida como vínculo entre as pessoas, a cooperação e a disposição coletiva que permitem partilhar saberes e práticas de saúde. Destacam-se a fala, a escrita e a interação como meio comum de expressões e significações, os quais dão sentido ao planejamento da vida cotidiana de cada participante. A dinâmica pode ser considerada como uma proposta ousada de comunicação popular. Por se constituir em uma atividade que apresenta novos objetos de reflexão e ação em saúde, que facilita o aporte de temas cotidianos comunitários, a condução exige novas habilidades e interesses, muitas vezes desconsiderados por parte dos profissionais das equipes e da população. Ressaltam-se ainda as possibilidades do 'bingão da saúde' servir como espaço de enfrentamentos ideológicos e políticos locais.

Em suma, definem-se três momentos que combinam o ciclo dinâmico do espaço: a evidência do tema e das situações disparadoras que compõem a realidade do bairro; o encontro, a escuta, o registro e a interlocução de vivências e experiências em saúde; e o jogo com as palavras e as interações comunitárias em saúde. 


\section{A evidência colegiada do tema pelo contato da vida cotidiana}

Este momento corresponde à definição do tema, das situações por ele possíveis de serem evidenciadas na comunidade e do planejamento a ser adotado para a realização do 'bingão da saúde'. Adotam-se, basicamente, duas frentes de trabalho: por um lado, é a partir do contato e diálogo diários entre profissionais e usuários do serviço que se registram temas e situações de interesse a serem levados ao encontro, na ocasião em que acontece o bingo. Esses temas são complementados pelas sugestões da população, depositadas na caixa de sugestões da unidade. Baseado nessas duas frentes, o grupo define o tema a ser levado para o encontro e seleciona os moderadores, recursos e estratégias para sua realização. Estes temas buscam espelhar o cotidiano de vida e saúde do bairro, bem como provocar reflexões para a superação e conquistas de projetos comuns. A divulgação do encontro é feita por meio de cartazes informativos fixados nos estabelecimentos sociais do bairro, tais como mercado, sacolão, loja de roupas, papelaria, igreja e nas instalações da USF. Outro meio de divulgação é a distribuição de panfletos impressos na própria unidade de saúde e o diálogo com os moradores durante as visitas domiciliares realizadas pelos profissionais de saúde. Propõe-se a utilização de recursos videofonográficos, impressos, referenciais bibliográficos do Ministério da Saúde, materiais de artesanato, teatro, dança e música como meio de comunicação e criação coletiva, apontando o segundo momento da experiência.

\section{O encontro, a interlocução e a interação comunitária em saúde}

Os encontros do 'bingão da saúde' acontecem uma vez por mês, com duração de duas horas, no período noturno, nas instalações da USF Romeu Tortorelli. São realizados em um pequeno espaço adaptado de garagem (diariamente utilizado como sala de espera), com as cadeiras dispostas em roda, uma mesa e os recursos a serem utilizados no encontro. Ilumina-se melhor o local; abre-se o portão da garagem e o convite é estendido aos usuários que esperam as consultas agendadas. Aos poucos, a população se aproxima, se reconhece e orienta o início da atividade. Participam do encontro, em sua maioria, crianças, senhoras, jovens, representantes comunitários e profissionais do serviço. É comum a presença de pessoas de outros bairros, no intuito de levar a ideia para seus locais de origem. Em roda, a atividade se inicia com a apresentação dos participantes, sempre de forma interativa e criativa, e com a explicação do funcionamento: um moderador apresenta a finalidade e abre espaço para a fala dos presentes, provocando-os a explanar suas expectativas e a relatar vivências que se relacionem com o tema a ser trabalhado. Inicia-se uma discussão aberta e livre sobre o tema, na qual 
os residentes multiprofissionais e os agentes comunitários de saúde atuam como moderadores. Este momento é aberto aos relatos, vivências, inquietações, medos, sugestões, reclamações, desabafos, entre outras necessidades da população. Busca-se estimular a comunicação entre os participantes, bem como ressaltar suas falas, relacionando-as à realidade do serviço. De forma concomitante, um segundo moderador sistematiza e escreve a ideia central de cada fala em um quadro visível por todos no local. Num momento seguinte, o grupo destaca as palavras-chave que irão compor as cartelas para o jogo do bingo. As palavras são numeradas para facilitar o preenchimento das cartelas. E assim a atividade se inicia.

\section{O jogo com as palavras e as mobilizações comunitárias em saúde}

As cartelas para o jogo (em branco) são confeccionadas pelos próprios participantes, que escolhem as palavras (ou números correspondentes) com as quais mais se identificam, referentes às falas sobre o tema em questão. Um terceiro moderador se responsabiliza pela confecção dos papeizinhos com as palavras (ou números correspondentes) para o sorteio. É comum o grupo indicar uma criança para ajudar na 'cantada' das palavras (ou números). Sequencialmente, as pessoas, auxiliadas pelos moderadores, vão marcando as palavras sorteadas em suas cartelas. Prendas trazidas pelos participantes são entregues aos primeiros que fecharem a cartela. Em caso de empate, a comunidade estabeleceu como regra que o vitorioso é aquele que tiver o número maior em sua cartela. O momento é finalizado com muita alegria, palavras de força coletiva, abraços e pactuação para um novo encontro.

\section{O processo}

Nesse pouco mais de um ano de 'bingão da saúde', as situações abordadas trataram da dinâmica cotidiana, das inquietações coletivas e das estratégias de mobilização no bairro. O processo de organização, planejamento e divulgação se inicia no mês de junho de 2007 nas reuniões do CGL da unidade de saúde. Após alguns meses de discussões, o primeiro encontro foi realizado em setembro, permeado de expectativas em relação à repercussão da proposta junto aos usuários. Nesse primeiro encontro, a participação foi pequena: três conselheiros, seis profissionais da unidade e apenas dois membros da comunidade. Realizaou-se a exposição da proposta e da importância da escolha coletiva dos temas. De forma consensual, foi conversado a respeito do olhar de cada participante em relação ao momento atual da comunidade e do serviço de saúde local. Na discussão saíram palavras que relatavam o 
comodismo, a falta de vontade e o desinteresse da população pelos assuntos que interessavam a própria comunidade. Concomitante a isso, as pessoas falaram sobre a necessidade de união, espaços para debate e mais informações sobre saúde no sentido de iniciar uma forma de mobilização comunitária no bairro. Aproveitando essas colocações, os profissionais instigaram os participantes a refletir sobre o conceito de saúde e de estar saudável. Emergiram daí discussões interessantes nas quais as pessoas foram se reconhecendo como um coletivo e percebendo o quanto a falta de uma área de lazer no bairro dificultava os encontros, a troca de idéias, as atividades físicas, as brincadeiras com crianças, dentre outras atividades, e influenciava diretamente na saúde individual e coletiva local. Como alavancas para um início de mudanças, surgiram palavras como participação, projetos coletivos, força, organização e iniciativa. A atividade foi encerrada com desejos de novas conquistas, esperança para um processo de mudança e o bingo como brincadeira das coisas sérias que foram conversadas.

No segundo encontro, debateu-se a temática saúde e cuidado e exibiu-se um filme em forma de peça teatral sobre integralidade em saúde (Universidade Federal do Piauí, 2006). Após a apresentação, discutiram-se as percepções individuais sobre o filme e a correlação com a realidade dos atendimentos e serviços. O grupo relatou a sensação de rapidez no atendimento e da não escuta do paciente; a sensação de descrença no serviço; a falta de esclarecimentos pelo profissional; e a falta de respeito. Entre outros assuntos levantados, destacam-se: a relação público-privado do sistema de saúde; a saúde como mercadoria; o direito do usuário e o dever do profissional; e a fragmentação do cuidado e dos conflitos profissionais.

Entender a equipe mínima da ESF (Brasil, 2004) foi a conversa do terceiro encontro. A utilização de uma dinâmica introdutória, mais interativa, quebrou a barreira inicial entre profissionais e usuários, deixando as pessoas à vontade para expressarem suas opiniões e dúvidas quanto à proposta da equipe e funcionamento da unidade. A integração e o clima de coletividade foram marcantes, bem como o grande número de crianças presentes no espaço. A presença das crianças (de forma constante a partir deste dia) vem possibilitando que elas frequentem e vivenciem a unidade em situações para além do adoecimento e do tratamento, em que se fazem presentes, sobretudo, o acolhimento, o estímulo e a valorização de saberes e do cuidado. Este encontro pôde contribuir para a formação de novos ideários de saúde e do espaço da unidade, reconhecida como centro de convivência, de mobilização, informação, cultura e lazer para a comunidade (Pedrosa; Pereira, 2007). Nessa perspectiva, o espaço passou a se configurar como meio de cuidado, estimulando a emancipação, interação social, o autocuidado, a melhoria da saúde e interação do ambiente familiar. A partir das trocas interpessoais, evidenciaram-se o contato e a percepção do outro. 
O último encontro de 2007 foi marcado pela avaliação das atividades realizadas e confraternização de um grande número de participantes. O fato de as moderadoras daquele dia terem declamado poesias de forma teatralizada e interativa fez com que todos se emocionassem e se sentissem como parte de uma única rede. O encontro demonstrou a evolução da apropriação do significado do espaço e do sentimento de fazer parte da comunidade ao se trazer uma prenda, sugerir uma atividade e fazer apresentações culturais. Após este encontro, houve uma pausa da atividade devido ao recesso de fim de ano e dos desencontros dos profissionais envolvidos na execução do espaço.

Nesse ínterim, os usuários sentiram-se mais seguros em colocar suas inquietações em espaços para além do 'bingão da saúde'. Aumentaram os relatos de queixas constantes quanto à assistência prestada, à espera no atendimento, às consultas longinquamente agendadas, entre outros problemas que acarretaram na bandeira de luta por uma nova unidade de saúde no bairro, justificada pela grande demanda populacional atendida e pelo amplo território adscrito da USF.

Na retomada do 'bingão da saúde' em março de 2008, reinicia-se o processo de escolha temática e de divulgação deste espaço na comunidade. Devido ao fato de a maioria das pessoas presentes nunca terem participado da experiência, as situações emergidas levantaram questões relacionadas às queixas individuais de morbidades e risco de saúde. Apesar da percepção dos moderadores sobre a existência de posturas passivas da população, à espera de respostas diretas, as conversas foram sendo delineadas de forma que as dúvidas fossem sanadas a partir dos conhecimentos prévios e vivências de cada participante. Na avaliação deste encontro, as pessoas saíram muito satisfeitas, dizendo que pretendiam voltar ao espaço e chamar mais pessoas para participar.

Nas comemorações da Semana Mundial da Saúde, em abril daquele ano, o encontro abordou as situações de saúde, o direito à saúde, o lazer, as atividades físicas, os estilos de vida, a mobilização e a participação popular no bairro. Pôde-se perceber um amadurecimento significativo do reconhecimento em relação à importância da atividade e das colaborações por parte de todos os envolvidos. As discussões encaminharam propostas de superação das dificuldades relatadas: de entender os direitos da população e o funcionamento da USF; de como contestar junto a gestão municipal os problemas e as necessidades locais de saúde; e organização pela equipe de momentos de educação para a população sobre o serviço utilizando espaços de salas de espera, de acolhimento (Brasil, 2006b), das consultas e dos grupos na USF.

No sexto encontro, a temática debatida destacou as necessidades da comunidade e a importância da mobilização do bairro para os preparativos de reunião anual do Orçamento Participativo municipal (OP) (São Carlos, 2008), que define as prioridades para os gastos públicos. Houve um interesse cole- 
tivo em saber o que significava esta instância. Entre outras necessidades do bairro, definiu-se a nova USF como principal prioridade local. Junto a líderes comunitários, encaminhou-se a proposta de participação de todos na reunião do OP e enfatizou-se o papel fundamental de multiplicadores da participação entre amigos e vizinhos. A participação da comunidade no OP foi maciça e resultou na conquista da nova USF Romeu Tortorelli! Vivenciar a defesa e a votação da proposta foi uma experiência única para os membros da equipe presentes, pois puderam sentir a vontade e a força coletiva da comunidade.

O sétimo encontro foi contemplado com a comemoração dessa conquista pela construção de cartazes com frases, desenhos e pinturas que expressaram toda a beleza e o suor do movimento comunitário realizado. Realizouse uma festa junina como forma de comemoração da conquista.

No último encontro registrado do 'bingão da saúde', em julho de 2008, o tema debatido foi esporte, lazer, atividades físicas e saúde. Os moderadores criaram uma encenação teatral interativa que estimulou os presentes a pensar nas possibilidades de lazer existentes no bairro e na cidade. Esta reflexão levantou a percepção de que existem pouquíssimos espaços públicos na comunidade destinados a esse fim. Em seguida, discutiu-se a relação entre lazer, atividades físicas e saúde; e a importância e necessidade da existência de espaços para estas atividades, bem como os meios de mobilização para conquistá-los. Fazendo um paralelo com essa discussão, algumas pessoas presentes expuseram, de forma bastante emocionada, sobre o quanto o 'bingão da saúde' é um espaço de lazer presente regularmente no bairro; a conquista das novas amizades e o fortalecimento de outras; o prazer em vir para a unidade de saúde sem estar doente; e os grandes ganhos pessoais como, por exemplo, a melhora da autoestima. No encontro, surgiram palavras como: brincadeiras, caminhada, baile, crochê, centro da juventude, coral, teatro infantil, centro comunitário, acolhimento e apoio. Nesse encontro, três ganhos importantes foram observados no que se refere à apropriação da atividade pela comunidade: uma pessoa da comunidade, espontaneamente, explicou o funcionamento do 'bingão' para todos os participantes; a escolha do tema a ser trabalhado no mês posterior foi decidida pelos próprios participantes (meio-ambiente); e três pessoas da comunidade se dispuseram a organizar previamente, junto com a equipe da USF, o encontro do mês de agosto de 2008.

\section{Considerações finais}

O 'bingão da saúde' vem representando, portanto, um conjunto de novas práticas inauguradas na USF. Ao entender o coletivo como ator da produção de sua saúde, encara-se o cotidiano do bairro como o cenário de reflexão e 
intervenção (Monken e Barcellos, 2005; Pereira e Barceloos, 2006), dando vida à ideia da indissociabilidade entre os saberes profissionais e populares em saúde (Brasil, 2007). O exercício continuado do 'bingão da saúde' tem se mostrado desafiador e, ao mesmo tempo, inovador na USF Romeu Tortorelli, haja vista as dificuldades da equipe em organizar seu trabalho e incorporar a atividade como prática apoiadora do controle social e do cuidado na USF.

Deste cenário, entende-se que reinventar os espaços tradicionalmente instituídos de controle social se faz cada vez mais necessário no atual contexto do SUS local. O caráter diferenciado e informal do encontro permite a quebra da barreira invisível entre profissionais de saúde e população - o que fortalece o vínculo profissional-usuário e promove uma verdadeira aproximação entre o serviço e a comunidade. A proposta é justamente ecoar as vozes da sabedoria popular no íntimo das vivências cotidianas, contrapondo as propostas verticalizadas de participação e de controle social comumente estruturadas por profissionais da saúde.

É neste movimento que o 'bingão da saúde' é reconhecido, entre outras iniciativas, como um meio de educação para a cidadania, fomentando a mobilização comunitária e estimulando o protagonismo de sujeitos de forma criativa e instigatória. Da troca de vivências surgem as mudanças de postura entre a equipe e o usuário, as quais fortalecem a gestão compartilhada dos serviços ou das iniciativas sociais de seus atores e a participação social. 


\section{Notas}

1 Docente e pesquisador do Centro Universitário Padre Anchieta (Unianchieta), Jundiaí, São Paulo, Brasil. Mestre em Saúde Pública pela Escola Nacional de Saúde Pública Sergio Arouca (Ensp/Fiocruz). Especialista em Saúde da Família e Comunidade (Residência multiprofissional) pela Universidade Federal de São Carlos (UFSCar). <bruno.bechara@gmail.com> Correspondência: Unianchieta, Secretaria, Curso de Terapia Ocupacional, Campus Universitário Prof. Pedro C. Fornari, Avenida Doutor Adoniro Ladeira, 94, Vila Jundiainópolis, CEP 13210-800, Jundiaí, São Paulo, Brasil.

2 Fisioterapeuta. Mestranda em Fisioterapia pela Universidade Federal de São Carlos (UFSCar). Especialista em Saúde da Família e Comunidade (Residência multiprofissional) pela Universidade Federal de São Carlos (UFSCar). <alinealmeida7@yahoo.com.br>

3 Farmacêutico. Especialista em Saúde da Família e Comunidade (Residência multiprofissional) pela Universidade Federal de São Carlos (UFSCar). <lucasbs@gmail.com>

4 Fonoaudióloga. Mestranda em Saúde Pública pela Faculdade de Saúde Pública da Universidade de São Paulo (USP). Especialista em Saúde da Família e Comunidade (Residência multiprofissional) pela Universidade Federal de São Carlos (UFSCar). $<$ carlasoleman@yahoo.com.br>

5 Professora associada da Universidade Federal de São Carlos (UFSCar), São Carlos, São Paulo, Brasil. Doutora em Enfermagem pela Escola de Enfermagem de Ribeirão Preto da Universidade de São Paulo (USP). <ogata@power.ufscar.br>

\section{Referências}

ACIOLI, Sônia. Participação social na saúde: revisitando sentidos, reafirmando propostas. In: PINHEIRO, Roseni; MATTOS, Ruben (Org.). Construção social da demanda. Rio de Janeiro: Cepesc/Uerj; Abrasco, 2005.

BRASIL. Lei n. 8142/90. Dispõe sobre a participação da comunidade na gestão do Sistema Único de Saúde (SUS) e sobre as transferências intergovernamentais de recursos financeiros na área da saúde e dá outras providências. Diário Oficial da União. Brasília, 28 dez. 1990.

Ministério da Saúde. SecretariaExecutiva. Núcleo Técnico da Política Nacional de Humanização. HumanizaSUS: equipe de referência e apoio matricial. Brasília:
Ministério da Saúde, 2004. 16 p. Série B. Textos Básicos de Saúde.

Ministério da Saúde. Secretaria de Atenção à Saúde. Núcleo Técnico da Política Nacional de Humanização. HumanizaSUS: documento base para gestores e trabalhadores do SUS. 3. ed. Brasília: Ministério da Saúde, 2006a. 52 p. Série B. Textos Básicos de Saúde.

Ministério da Saúde. Secretaria de Atenção à Saúde. Núcleo Técnico da Política Nacional de Humanização. Acolhimento nas práticas de produção de saúde. 2. ed. Brasília: Ministério da Saúde, 2006b, 44 p. (Série B. Textos Básicos de Saúde). 
Ministério da Saúde. Secretaria de Atenção à Saúde. Núcleo Técnico da Política Nacional de Humanização. Clínica ampliada, equipe de referência e projeto terapêutico singular. 2. ed. Brasília: Ministério da Saúde, 2007, 60 p. Série B. Textos Básicos de Saúde.

CAMPOS, Gastão W. S. Saúde Paideia. São Paulo: Hucitec, 2003.

CAMPOS, Gastão W.S.; DOMITTI, Ana Carla. Apoio matricial e equipe de referência: uma metodologia para gestão do trabalho interdisciplinar em saúde. Cadernos de Saúde Pública, Rio de Janeiro, v. 23, n. 2, p. 399407, 2007.

CREVELIM, Maria Angélica; PEDUZZI, Marina. A participação da comunidade na equipe de saúde da família: como estabelecer um projeto comum entre trabalhadores e usuários? Ciência \& Saúde Coletiva, Rio de Janeiro, v. 10, n. 2, p. 323-331, 2005.

FREIRE, Paulo. Pedagogia do oprimido. 6. ed. Rio de Janeiro: Paz e Terra, 1979.

Pedagogia da autonomia: saberes necessários à prática educativa. São Paulo: Paz e Terra, 1996.

INTEGRALIDADE: desejo e realidade. Produção do Laboratório de Artes Cênicas da Universidade Federal do Piauí (UFPI). Coordenação de Cleiber Silveira. Teresina: UFPI, 2006. 1 vídeo.

MONKEN, Maurício; BARCELLOS, Christovam. Vigilância à saúde e território utilizado: possibilidades teóricas e metodológicas. Cadernos de Saúde Pública, Rio de Janeiro, v. 21, n. 3, p. 898-906, 2005.

PAIM, Jairnilson. Por um planejamento das práticas de saúde. Ciência \& Saúde Coletiva, Rio de Janeiro, v. 4, n. 2, p. 243-261, 1999.
PEDROSA, José Ivo dos S.; PEREIRA, Esdras D. S. Atenção Básica e o controle social em saúde: um diálogo possível e necessário. Revista Brasileira de Saúde da Família, ed. especial, p. 7-22, 2007.

PEREIRA, Martha P. B.; BARCELLOS, Christovam. O território no Programa de Saúde da Família. Revista Brasileira de Geografia Médica e da Saúde, Uberlândia, v. 2, n. 2, p. 47-55, 2006.

SÃO CARLOS (Prefeitura). Decreto n. 142, de 5 de outubro de 2001. Regulamenta a lei municipal n. 12.587, de 17 de julho de 2000, que dispõe sobre a organização dos conselhos gestores nas unidades de saúde do Sistema Único de Saúde e dá outras providencias. São Carlos, 200.

Universidade Federal de São Carlos. Secretaria Municipal de Saúde de São Carlos. Programa de Residência Multiprofissional em Saúde da Família e Comunidade. Catálogo, 2007.

Orçamento Participativo. 2008. Apresenta regimento interno sobre orçamento participativo. Disponível em: < http://ped. linkway.com.br/download/op/regimento \% $20 \mathrm{do} \% 20 \mathrm{op} \% 202005 . \mathrm{PDF}>$. Acesso em: 30 jun. 2008 .

VALLA, Victor Vincent. Sobre participação popular: uma questão de perspectiva. Cadernos de Saúde Pública, Rio de Janeiro, v. 14, supl. 2, p. 7-18, 1998.

VASCONCELLOS, Eymard M. Educação popular: de uma prática alternativa a uma estratégia de gestão participativa das políticas de saúde. Physis: Revista de Saúde Coletiva, Rio de Janeiro, v. 14, n. 1, p. 67-83, 2004.

Recebido em 22/12/2009

Aprovado em 29/03/2010 